\title{
LA BOTICA DEL REAL HOSPITAL DE MINEROS EN LA ESTRATEGIA ASISTENCIAL DEL ESTABLECIMIENTO DE ALMADEN, SIGLOS XVIII Y XIX
}

\author{
Alfredo Menéndez Navarro
}

1. Introducción. Asistencia médica y trabajo en las Minas de Almadén

El dispositivo asistencial desplegado a mediados del siglo XVIII por los responsables de las Minas de Almadén constituye, con toda certeza, un caso difícilmente equiparable en el panorama laboral de nuestro país. La extraordinaria insalubridad del proceso productivo del mercurio, junto a su papel clave en la política financiera colonial española, convirtieron al enclave minero de Almadén en un ejemplo excepcional del papel otorgado a la medicina en las relaciones laborales. La falta de mano de obra, producto del rápido deterioro orgánico que sufrían los operarios y de la incapacidad de la población de Almadén para suministrar un contingente laboral suficiente, se convirtió en uno de los factores limitantes de la producción de azogue y, por ende, de la obtención de plata en las minas americanas, practicada mayoritariamente por el proceso metalúrgico de la amalgamación. Esta situación, agravada durante los decenios centrales del Setecientos ante las pretensiones de incrementar las sacas de azogue; impulsó a la Real Hacienda española, máxima responsable de la explotación, a adoptar un 
conjunto de medidas de amplio espectro destinadas a garantizar la oferta de fuerza de trabajo.

El Establecimiento minero apostó por un modelo de producción social y biológicamente costoso. La escasa o nula mejora experimentada en las condiciones de trabajo, aun siendo asequibles a la tecnología minera de la época, configuró un proceso productivo basado en la incorporación de un elevado número de operarios expuestos a un alto grado de deterioro biológico. Los dirigentes de las Minas optaron por pagar el «precio social» de este modelo en forma de diversas transferencias al margen de la relación salarial (1).

Una buena parte de estas transferencias se articularon en torno al Real Hospital de Mineros, fundado en 1752 (2). El nosocomio, destinado específicamente al colectivo laboral de las Minas y sus familias, contribuyó de manera decisiva en el mantenimiento de ciertas cotas de producción, facilitando la recuperación de los trabajadores durante los frecuentes períodos de inactividad a que se veían expuestos por motivos de salud. Junto a esta contribución asistencial, el Hospital de Mineros instrumentó mecanismos para ampliar su radio de acción. Entre estos cabe destacar la dotación de una botica, destinada no sólo a satisfacer las necesidades del nosocomio, sino las de una población que superaba los límites de la propia villa minera. La creación de una adecuada oferta de medicinas se reveló como uno de los medios más eficaces para ampliar la cobertura asistencial, a la vez que suponía un abaratamiento de los costes sanitarios.

En el presente trabajo pretendemos analizar el papel jugado por la botica en la estrategia asistencial de las Minas durante el período de máximo auge de la actividad del Hospital de Mineros. En esta época, que se extiende desde los años ochenta del siglo XVIII hasta el primer decenio del siglo XIX, los responsables del nosocomio adoptaron distintas medidas para facilitar el acceso de los trabajadores a las medicinas en condiciones ventajosas. Para ello resulta imprescindible acudir a la documentación generada por la propia botica y el hospital conservada en el Archivo Histórico Nacional de Madrid (A.H.N.) bajo la denominación de «Minas de Almadén». Otro fondo de interés para nuestro estudio se halla depositado en el Departamento de Historia Económica de la Universidad Complutense de Madrid, material que consignaremos con la abreviatura de A.D.H.E. 


\section{El suministro de medicinas a la población de Almadén. La Botica del Real}

Hospital de Mineros

El Hospital de Mineros no contó con una botica propia para atender sus necesidades hasta el año 1782. Con anterioridad a esta fecha, el suministro de medicamentos corrió a cargo de los boticarios instalados en la localidad, quienes mantenían un concierto con las Minas para el abastecimiento. El boticario; que no percibía salario alguno de forma fija, estaba obligado a proveer los medicamentos necesarios para los forzados y esclavos empleados en los trabajos subterráneos que se hallaran enfermos, así como para las necesidades de las máximas autoridades administrativas de las Minas, la Superintendencia, la Contaduría y la Pagaduría. El boticario recibía el importe de las recetas despachadas al precio tasado por el médico del Establecimiento (3).

Esta fórmula se mantuvo prácticamente inalterada hasta mediados del siglo XVIII. En 1750, el concierto afectaba a las dos oficinas de farmacia existentes en la villa. Ambas suministraban alternativamente los medicamentos a los forzados y esclavos. Las medicinas se cobraban a la mitad del precio establecido en la Tarifa del Real Protomedicato y gratis para los oficiales de la Superintendencia, Contaduría, Pagaduría y sus familias. Precisamente, fue el incremento en el número de éstos el argumento que esgrimieron los boticarios para revisar las condiciones del contrato en 1756 . Los oficiales con derecho a "obención" de medicamentos, como se denominaba esta exención, pasaron de cuatro, a mediados de la centuria, hasta diez, en 1757.: La nueva contrata, aprobada en enero de ese año, contemplaba el pago à los boticarios de las $2 / 3$ partes del precio consignado en la citada tarifa, manteniéndose la gratuidad para los mismos empleados y sus familias (4).

El grueso de trabajadores libres y vecinos de Almadén accedían a las medicinas mediante las boticas de la localidad. Un acceso difícil, si tenemos en cuenta los limitados ingresos de los mineros, reducidos aún más durante los períodos de inactividad laboral que conllevaba la enfermedad. La gratuidad sólo estaba contemplada para los forzados y para un limitado grupo de dependientes, que gozaban, por otro lado, de unas amplias dotaciones económicas. La única vía complementaria de que disponían los operarios para sufragar este capítulo eran las limosnas concedidas por las Minas, que incluían con frecuencia el pago de las medicinas consumidas en la curación. Esta fue la opción mayoritaria durante la construcción del nuevo hospital, que se prolongó entre 1755 y 1774. Los recursos económicos cap- 
tados para su fundación permitieron tanto la asistencia en el Hospital de la Caridad, un pequeño establecimiento dependiente del Cabildo Municipal, como la concesión de un elevado número de ayudas en metálico para los enfermos que permanecían en sus domicilios. Un porcentaje importante de estos gastos, el $30 \%$ en Almadén y el 15\% en Almadenejos, se invirtieron en el pago de las medicinas consumidas (5).

Tras la entrada en funcionamiento del Hospital de Mineros en $1774 \mathrm{y}$, principalmente, "con el auge de su actividad asistencial en los años finales de esa década, este modelo de provisión resultó insuficiente. Dos fueron los argumentos barajados para justificar la necesidad de dotar una farmacia propia. En primer lugar, asegurar la calidad de las medicinas:

«...observando que en las tres Boticas establecidas en dicha Villa faltaban muchos medicamentos de los necesarios para la curación de los enfermos (no obstante de despacharse en ellas las recetas que los contenían) y que además, por no perder su valor, usaban los boticarios de los añejos y disipados que no podían surtir buen efecto en grave daño de la salud pública,,$\ldots »(6)$ :

En segundo lugar, el sistema resultaba excesivamente oneroso a las arcas del nosocomio ante el volumen de medicinas necesarias. Los perjuicios. económicos al hospital fueron el otro argumento de peso:

«en grave daño... de los intereses del Hospital, que había invertido en los años de 1779 y los dos siguientes 23.865 reales y 19 maravedíes de vellón en sólo el pago de las medicinas suministradas por los referidos boticarios en dichos tres años, siendo así que en el mismo Hospital se laboreaba una gran parte de ellas por el ahorro, que de esto resultaba,...» (7).

De hecho, la propia crisis financiera que sufrió el nosocomio a finales de los setenta, producto de la duplicación de nivel de actividad en ausencia de nuevos ingresos económicos, motivó la suspensión de las obras de habilitación de la botica, iniçiadas en esos años (8). La propuesta definitiva corrió a cargo del Superintendente José Agustín Castaño en abril de 1782. La R.O. de 24 de mayo de ese año aprobó la petición, dotando las plazas de regente y mancebo, entrando la botica en funcionamiento en el mes de agosto (9).

Las normas definitivas para su manejo aparecen recogidas en las ordenanzas del Real Hospital de 1791. En lo que respecta a la dotación de per- 
sonal, cabe destacar la inclusión de un mozo para atender a las labores menos específicas y la exigencia expresa al regente de dedicación exclusiva:

«No ha de poder tener de su cuenta Botica pública en dicha Villa, u otro cualquiera pueblo, ni menos comerciar en géneros o útiles que correspondan a su facultad» (10).

Pero lo más sobresaliente es, sin duda, el protagonismo asignado a la nueva oficina. En sólo unos años, la botica asumió el suministro de medicinas a la casi totalidad de las dependencias del Establecimiento y colectivos vinculados a las Minas, ampliando su cobertura más allá de la propia villa de Almadén. El conjunto de funciones desempeñadas pueden agruparse bajo cinco epígrafes:

I. El abastecimiento de la enfermería del Hospital de Mineros de Almadén. Era su principal labor, y la que acaparó el mayor volumen de recursos. El regente de la botica y el mancebo mayor se incorporaron a la dinámica asistencial del nosocomio participando en las visitas que practicaban diariamente los facultativos a los enfermos, momento en el que se realizaban las prescripciones. Otro centro asistencial abastecido directamente por esta botica fue el pequeño hospital creado en el departamento de Almadenejos, una población surgida al hilo de nuevos descubrimientos de mineral. Esta situación se mantuvo hasta la dotación, en los primeros años del siglo XIX, de un botiquín en el nosocomio de este departamento.

II. El suministro a la enfermería de la Real Cárcel de Forzados y a los "presos libres». Las Minas de Almadén incorporaron mano de obra forzada como medio de garantizar la realización de las tareas más insalubres. El contingente de reclusos y esclavos varió considerablemente a lo largo del tiempo, pasando de los 30 en 1566, fecha de su incorporación, hasta superar los 250 en los años centrales del Setecientos (11). Desde 1568, los forzados contaron con una enfermería instalada en los aledaños de la cárcel donde eran atendidos por los facultativos de las Minas. El peso asistencial de esta enfermería disminuyó de forma importante tras la retirada de los réclusos de los trabajos de interior en 1755, a raíz de un incendio que paralizó la explotación del que fueron considerados responsables. Este proceso culminó con el ingreso progresivo de los forzados enfermos a las sálas del hospital en los años ochenta y la supresión de la enfermería en 1793 (12). Bajo la paradójica denominación de "presos libres» se englobaba a un colectivo de reclusos que ingresaban en la prisión de Almadén sin estar con- 
denados a galeras. Una parte de ellos, cuyos delitos eran considerados menos graves, se ocupaban en las Minas a cambio de un jornal diario de cuatro reales (13). La manutención de estos "presos libres» corría a cargo del Real Hospital, principalmente durante la enfermedad, en que también se les suministraban gratuitamente las medicinas.

III. Despacho de medicinas para los dependientes con "obención de botica». Como ya hemos mencionado, los oficiales de las principales dependencias administrativas del Establécimiento gozaron tradicionalmente de la exención del pago de las medicinas. El grupo de beneficiarios de esta prerrogativa se amplió en 1791 a algunos de los dependientes del Hospital de Mineros. Los salarios del mayordomo, el oficial de libros y los dos capellanes con que contaba el nosocomio incluían el derecho a la "asistencia de médico, cirujano y botica» de forma gratuita, derecho que se extendió, aunque no constase explícitamente en el reglamento, a los tres facultativos.

IV. Suministro para las mulas y bueyes de la Real Casa Factoría. Esta actividad fue la menos relevante de la botica y se realizaba mediante las recetas de los albéitares encargados del cuidado de los animales empleados al servicio de las Minas.

V. Despacho de medicinas al común. La venta de preparados farmacéuticos a los habitantes de la localidad y villas cercanas brindó a los responsables del Establecimiento la posibilidad de incidir de nuevo sobre las condiciones de recuperación de los trabajadores. La oferta de medicinas en condiciones asequibles se reveló no sólo como un mecanismo que favorecía la restitución de la salud de los operarios sino como una fórmula eficaz para evitar su ingreso al hospital.

La Tabla 1 ofrece la evolución del gasto efectuado por la botica del nosocomio desde su puesta en marcha, en agosto de 1782, hasta 1789. El enorme incremento de las medicinas consumidas en las enfermerías - durante los primeros cinco meses de funcionamiento el consumo fue casi equivalente al de los tres años anteriores juntos- es un claro indicador del creciente volumen de actividad asistencial desplegado por el hospital. El gasto medio anual se situó por encima de los 40.000 reales, con un máximo durante la crisis epidémica de 1784-1786. 
Tabla 1

EVOLUCION DEL GASTO DE LA BOTICA DEL REAL HOSPITAL DE MINEROS POR CAPITULOS, 1782-1789

(cifras en reales de vellón).

\begin{tabular}{lcrcrcc}
\hline & I & II & III & IV & V \\
\hline $1782(1)$ & 17.946 & 2.893 & n.d. & n.d. & n.d. \\
1783 & 42.072 & 12.187 & 2.086 & n.d. & n.d. \\
1784 & 64.679 & 10.606 & 2.582 & n.d. & n.d. \\
1785 & 60.603 & 16.880 & 1.942 & 82 & 16.690 \\
1786 & 77.152 & 9.007 & 3.660 & 166 & 18.198 \\
1787 & 45.738 & 8.759 & 3.399 & 311 & 6.822 \\
1788 & 43.515 & 3.742 & 1.651 & 632 & 6.230 \\
1789 & 47.288 & 3.567 & 2.266 & 705 & 4.059 \\
\hline
\end{tabular}

I. Enfermerías de los hospitales de Almadén y Almadenejos.

II. Enfermería de la cárcel de forzados y «presos libres».

III. "Obenciones».

IV. Real Cása Factoría.

V. Despachado al común.

(1) Sólo los meses de agosto a diciembre.

Fuente: Relaciones anuales del importe de las medicinas suministradas por la Botica del Real Hospital de Mineros de Almadén. A.H.N., Minas de Almadén, leg. 10.

El segundo capítulo incluido en la Tabla, muestra una evolución acorde con el volumen de penados existente en la cárcel. El descenso del número de reclusos experimentado a partir de 1785 , junto a su progresivo ingreso en las salas del hospital, favoreció la reducción del gasto en este apartado.

El capítulo de venta al público revela más claramente algunas de las estrategias de los responsables de las Minas para facilitar el consumo de medicinas entre los trabajadores. El reglamento de 17.91 establecía un precio distinto para los operarios de las Minas: 
«El despacho de medicinas al común de dicha Villa o Lugares de su Inmediación al dinero contado o al fiado se practicará en virtud de recetas de médico o cirujano conocido, que también recogerá el regente cobrándose su valor, a los vecinos de Almadén y Lugares de su jurisdicción, descontada la tercera parte del que previene la Real Tarifa con respecto a la singular atención con que debe tratarse a los mineros y a que no sólo se desea el bien público en la calidad de los medicamentos, sino en su equitativo precio y, por su justo valor, las que se suministren para fuera de dicha Jurisdicción" (14).

Junto a la instauración de una tarifa reducida, se permitió la compra de medicinas al fiado. La venta en efectivo fue el medio habitual en los primeros años de funcionamiento. Desde agosto de 1782 hasta finales de 1784, el importe de las medicinas despachadas al público ascendió a 11.416 reales, de los que sólo una tercera parte ( 3.825 rs.) se hizo al fiado. Esta tendencia se invirtió en los dos años siguientes, reduciéndose los ingresos en efectivo al 37\% y 33\% del total despachado, respectivamente (15).

La documentación consultada refleja dos aspectos que debieron ser consustanciales a la venta al fiado: la frecuencia con que los vecinos no podían hacer frente al pago de las deudas contraidas y las dificultades que encontraban en su tarea los encargados del cobro de las medicinas fiadas. El reglamento de 1791 limitaba esta modalidad de despacho para los empleados de la administración de las Minas y los vecinos y «trabajadores conocidos y de quienes pueda cobrarse», a la vez que señalaba el «tiempo del pagamento de salarios y jornales devengados en las Minas» como el momento adecuado para ejecutar el reembolso de las cantidades fiadas. A pesar de estas precauciones, la realidad debió ser bien distinta, pues desde los primeros años de funcionamiento de la botica se acumularon las listas de medicamentos impagados. Resulta difícil cuantificar las deudas contraidas, pero, en Almadén, rara vez bajaba del centenar el número de vecinos que mantenían débitos (16). Un informe fechado en 1811, eleva a más de 25.000 reales el monto pendiente de cobro desde mayo de 1797, adeudado por un total de 150 vecinos de Almadén (17).

La renuncia, con cierta frecuencia, de los comisionados encargados del cobro confirma las dificultades inherentes a esta tarea. En 1789, dos de los comisionados presentaron su dimisión. Andrés Moreno, ayudante del oficial de libros de la Real Casa Factoría, argumentaba el exceso de trabajo y «lo penosa que es una cobranza de esta naturaleza». Razones similares esgrimió Mateo Azpeytia, oficial de libros del cerco de fundición, 
quien denunciaba el trato denigrante al que se veía sometido por los deudores (18).

La tendencia creciente a la adquisición de medicinas por este sistema motivó su suspensión en julio de 1787. Esta medida explica la considerable reducción que se observa en el volumen de medicinas despachadas al público desde ese año. Otro reflejo de esta disposición podría encontrarse en el incremento que sufrieron las medicinas dispensadas de forma gratuita a los enfermos que permanecían en sus domicilios. En 1786 y 1787 la cuantía aplicada a este fin no superó los 400 reales, mientras que sólo en 1788 ascendió a 736 y, en 1789, a algo más de 2.000 reales (19).

\section{La creación de una segunda botica}

A pesar de las dificultades para recuperar el importe, la venta al fiado volvió a ponerse en práctica en julio de 1788. Facilitar la provisión de medicinas a la población era la principal garantía de que los enfermos no acudirían al hospital, donde su mantenimiento generaba mayores gastos. Esta hipótesis se refuerza ante la decisión de los responsables del Establecimiento de dotar una botica en la localidad, dependiente de la del hospital, destinada exclusivamente a la venta al público, incluyendo el despacho de recețas para los individuos que gozaban de esta exención. La entrada en funcionamiento de esta nueva oficina, en mayo de 1791, estuvo precedida por la adquisición de las existencias de dos farmacias. En marzo de ese año, el Hospital de Mineros compró los efectos pertenecientes a una de las boticas establecidas en la villa tras la muerte de su propietario. En ese mismo mes, hizo otro tanto con las medicinas y útiles existentes en la del convento de San Francisco Extramuros de Chillón (20).

El balance económico de su actividad fue motivo de frecuentes controversias que ilustran algunas de las finalidades que animaron el proyecto. Las referencias al «manejo irregular» de esta dependencia se suceden desde las primeras fechas. En agosto de 1798, la Junta de Superintendencia, órgano que sustituyó transitoriamente al Superintendente al frente del Establecimiento, se hacía eco de las quejas del vecindario sobre la mala calidad y el elevado precio de las medicinas dispensadas. La Junta encargó al médico y al cirujano de las Minas que propusieran medidas para mejorar su gestión «que repercute con grandes gastos para el hospital» (21). El primer informe disponible sobre el coste económico data de mayo de 1800 , 
del que se desprenden dos conclusiones. El origen de la mala gestión estribaba en la falta de separación entre los artículos consumidos en la botica del hospital y la establecida en el pueblo, lo que imposibilitaba el conocimiento exacto de sus rendimientos. Además, en los dos años a que hace referencia el informe sólo se cobró en efectivo 5.700 reales, mientras que la cantidad invertida en la adquisición de las sustancias necesarias para su elaboración fue cinco veces superior,

. «...pues regularmente se consumen de 15.000 a 16.000 reales en cada año en este surtido; por donde se nota la diferencia que, lejos de resultar ganancia, antes tiene que expender el Hospital intereses suyos para tener provista la Botica» (22).

Frente a los reducidos ingresos en metálico, las cuentas arrojaron una cantidad cercana a los 19.000 reales despachados en concepto de "obencióni, perdonado por decretos del Superintendente y deudas de los vecinos. Junto a las pérdidas económicas, los responsables de las Minas se mostraron preocupados por los efectos del elevado importe de los medicamentos. En enero de 1801, el Superintendente decretó que el precio de los preparados no superase el consignado en la tarifa, argumentando el perjuicio económico derivado de esta situación:

«...pues las más veces, tal vez no pudiendo costear a las insinuadas medicinas, muchos pobres se verán precisados a pasar al Hospital para su curación y vendremos a parar en que siempre es en perjuicio de aquellos fondos [del Hospital]» (23).

La actitud intervencionista de las Minas también contó con algunos detractores. En 1804, Clemente José de Ortuño, capellán de hospital, se mostraba contrario al mantenimiento de esta segunda botica. Ortuño, que incluyó la propuesta entre un amplio plan de reformas de corte religioso, refutaba perjudicial para los intereses del Establecimiento la continuidad de esta dependencia que no solucionaba el problema del abastecimiento a los vecinos:

"Y si se adoptase el medio de suprimir la Botica, que el Real Hospital sostiene, única en el pueblo, y en la que gasta crecidas sumas, sin utilidad alguna, y se permitiese que se estableciesen en el pueblo dos o más. Boticas de Particulares; que a competencia se esmerasen en las operaciones Quí- 
micas y diesen las Medicinas fiadas, puesto que hay la mejor proporción para cobrar todos los meses al tiempo del pago de los sueldos y los jornales, es de esperar que, teniendo los pobres jornaleros, especialmente, la asistencia de los Facultativos de la Villa, la medicina fiada y libres del pago de los derechos parroquiales, es de esperar según su carácter, que se retraigan del Real Hospital, y que éste y la Real Hacienda tengan un ahorro muy considerable en cada año. Los más se van al Hospital cuando ya no les queda absolutamente con qué pagar la medicina y el entierro» (24).

La situación de la botica se hizo insostenible ante los problemas financieros que acosaron a las Minas tras la Guerra de la Independencia. La puesta en circulación de papel moneda para garantizar el pago de los salarios y su aceptación en la botica del pueblo provocaron, en sólo unos meses, su total desabastecimiento. En noviembre de 1811, el interventor informaba del estado deplorable que atravesaba esta dependencia ante la escasez de efectivo para reponer las sustancias necesarias. Entre otras medidas, proponía la prohibición temporal de realizar el pago con papel moneda,,

\footnotetext{
«...haciendo ver al público la precisa urgencia que lo motiva, hasta tanto que repuesta dicha botica de lo muy preciso, volviese a hacer el mismo - favor que hasta ahora ha hecho de admitir el referido papel» (25).
}

La prohibición se limitó a los forasteros y vecinos que no se ocupaban en las Minas, permitiendo a los operarios y empleados de la administración que continuaran adquiriendo medicinas mediante este sistema:

La supresión definitiva se decretó a finales de 1812, trasladándose a la botica del hospital todos los medicamentos y pertrechos (26). El cierre provocó la reacción de las autoridades municipales preocupadas por èl precario abastecimiento de la población, ya que tras la supresión sólo contaban con una botica en la localidad. La corporación solicitó el restablecimiento de este servicio o, en su defecto, su venta a algún particular. El Contador de las Minas se mostró tajante respecto a la primera eventualidad:

«El Establecimiento no puede volver a establecer botica en el pueblo por su cuenta porque la experiencia tiene acreditado que es ruinoso a los fondos del hospital este manejo,...» (27).

Mejor recibimiento tuvo la segunda, ya que, en opinión del Contador, la competencia obligaría a los boticarios a mejorar la calidạd de sus prepara- 
dos y a abaratar los precios. Las palabras del Contador no dejan lugar a duda sobre la trascendencia económica de un adecuado suministro a los vecinos:

«Para combinar la utilidad pública y el alivio del mineraje en sus enfermedades (que tal vez, por no sujetarse a una sola botica, preferirán ir a curarse al hospital, donde causarán más gastos) con las reflexiones que van expuestas, para no gravar al Establecimiento con la provisión de medicinas, como lo estaba antes, el medio más conforme parece el que se venda la botica suprimida...» (28).

La enajenación se realizó en 1813, imponiendo al nuevo propietario la obligación de mantener la oficina en Almadén.

\section{Las igualas de botica}

Hasta ahora hemos descrito dos de los mecanismos de intervención desarrollados por el Establecimiento para facilitar el consumo de medicinas a la población, la aplicación de precios reducidos para los operarios de las Minas y la venta al fiado. Ambas medidas, realizadas a través de la botica del Hospital de Mineros y, años más tarde, de la habilitada en la localidad, afectaron principalmente a los habitantes de Almadén, Almadenejos y Chillón. La botica del hospital extendió su radio de acción sobre otros pueblos sometidos a la jurisdicción de Almadén y suministradores tradicionales de mano de obra para las Minas. El establecimiento de igualas con las poblaciones cercanas de Alamillo, Saceruela y Gargantiel, iniciadas casi al mismo tiempo que comenzó a funcionar la botica del hospital, posibilitó ampliar la "cobertura» a un importante contingente de población.

Las igualas permitían el consumo de medicinas a cambio de una cantidad estipulada de trigo o, en su defecto, en metálico. Los censos de igualados se realizaban a mediados de agosto de cada año y en ellos se fijaba el montante total de granos a suministrar, cuya entrega se practicaba en igual mes del año siguiente. El trigo se destinaba al Pósito de Almadén y su importe, estipulado por el Superintendente, revertía a las arcas del Hospital de Mineros. Dos fueron las fórmulas seguidas para fijar la contribución familiar. La primera de ellas, ejecutada hasta 1787, establecía la contribución anual de cinco celemines de trigo por matrimonio y, por cada tres per- 
sonas miembros de la familia, además de éste, un celemín; cantidad que se incrementaba proporcionalmente si el núcleo familiar superaba este tamaño (29). Un año más tarde, entró en vigor el otro mecanismo que fijaba los siguientes cánones: por matrimonio, cinco celemines; por viudo o soltero; dos celemines y medio; igual cantidad para las viudas pudientes; por cada hijo mayor de 10 años, un celemín; quedando exentos de pagar los pobres de solemnidad y los hijos menores (30).

La inclusión en los censos era voluntaria. En el primer año en que se practicó la iguala, de agosto de 1783 a igual mes de 1784, el número de vecinos incluidos en Alamillo y Gargantiel fue de 144 y 28, respectivamente (31). Los datos disponibles sobre la población de estas localidades, pertenecientes a 1773, arrojan una cifra de 127 vecinos para la primera y 30 para la segunda, lo que confirmaría la amplia implantación de que gozó este sistema (32). Los datos del censo practicado en agosto de 1784 mantienen la misma tendencia.

En general, puede decirse que el sistema de igualas era favorable para la población. La estimación del importe de la contribución anual resulta siempre inferior al montante de las medicinas suministradas. El censo de Alamillo correspondiente al año 1784-1785 establecía una contribución de 57 fanegas y dos celemines de trigo que, a un precio medio de 35 reales la fanega, suponen 2:000 reales de vellón; cantidad ligeramente inferior a los 2.294 reales que importaba lo suministrado. La diferencia es mucho mayor en el censo de 1785-1786, pues, frente a una contribución similar, el consumo ascendió a más de 3.000 reales (33). A este déficit para el Hospital de Mineros hay que unir las dificultades que acompañaban al cobro de las contribuciones. Valga de ejemplo el caso de Saceruela. De un total de 535 celemines de trigo, fijados.en agosto de 1783, sólo fue posible recaudar 89 en el plazo acordado. Además, el Superintendente exoneraba del pago, con cierta frecuencia, a mineros imposibilitados o vecinos insolventes, por lo qué las contribuciones rara vez se cobraban en su totalidad (34).

Por otro lado, la iguala permitía redistribuir entre los vecinos el pago de la contribución. En 1807, la villa de Alamillo, que había suspendido la contrata con el Hospital de Mineros desde 1804, solicitó reincorporarse a este sistema. La elevación del precio de las medicinas hacía aconsejable establecer un nuevo método para fijar el gravamen que no perjudicase excesivamente los fondos del hospital. La fórmula propuesta abunda en el carácter equitativo de la iguala, estableciendo la cuota en función de las posibilidades económicas de los vecinos. El comisionado Miguel de Basterra propuso la división del vecindario de Alamillo en tres clases: «acomoda- 
dos, de un regular pasar y de miserables», distinguiéndolas según el número de yuntas que poseyeran. En el grupo de los miserables, donde incluía a los que carecían de ellas y "sólo se mantienen de su trabajo a jornal», estaban comprendidos los vecinos que se empleaban en las Minas. Las nuevas cuotas elevaban considerablemente el canon a las familias con medios, que pasaban a pagar 12 celemines por matrimonio, 4 por cada hijo mayor de siete años y otro tanto por cada criado. El incremento también era manifiesto para la segunda categoría de vecinos, obligados a entregar 8 celemines por matrimonio y uno y medio por cada hijo mayor de siete años. Los viudos, viudas y solteros con casa abierta, pagaban 4 celemines y dos y medio por cada hijo o sirviente. Sin embargo, las familias más desfavorecidas veían disminuir su cuota, reduciéndose de 5 a 4 los celemines que debían pagar por matrimonio, mientras que hijos, viudos y solteros mantenían la misma contribución. La medida producía una doble ventaja, ya que «además de que redunda en beneficio de los pobres, no se gravan los citados fondos de aquella casa de caridad» (35).

$\mathrm{El}$ 'grano procedente de las igualas, con las dificultades de recaudación ya comentadas, revertía entre los pobladores de Almadén, al aplicarse al Pósito de la Villa. La contribución anual oscilaba en torno a las 120 fanegas de trigo, cantidad de la que podía obtenerse algo más de 11.000 libras de pan bazo, o algunas menos de pan blanco, de mayor calidad: Es decir, la contribución de las igualas bastaría para asegurar el consumo anual de pan en el Hospital de Mineros durante un año de actividad media, aún en el supuesto de adjudicar a cada estancia hospitalaria una libra de pan, cantidad que se veía reducida en el caso de las medias raciones y dietas. La modesta contribución de las igualas no parece, por tanto, despreciable, máxime si tenemos en cuenta los frecuentes problemas de desabastecimiento que afectaron a la villa minera durante los primeros decenios del siglo XIX.

\section{El desmantelamiento asistencial}

La quiebra financiera de la Hacienda Pública tras la Guerra de la Independencia y la sangría económica que vivió el país durante las campañas carlistas provocaron un retroceso considerable en los presupuestos del Establecimiento minero, nutridos directamente de las arcas del Estado. La 
botica corrió la misma suerte que el resto del hospital, limitándose considerablemente su actividad.

En 1834, se suprimió la exención del pago de las medicinas que disfrutaba un reducido número de dependientes de las Minas:

«No estando autorizado por artículo alguno de ordenanza ni real resolución la costumbre de obención de botica del Superintendente, Contador, Tesorero y otros Empleados de estas oficinas, siguiéndose costosos abusos difíciles o imposibles de precaver por los mismos agraciados, he resuelto cese desde hoy la mencionada costumbre y que los empleados que gusten surtirse de la Botica del. Hospital, lo verifiquen sufriendo en cada mes el descuento correspondiente según el valor de las recetas» (36).

La prohibición se reiteró en 1839 ante la pretensión del cirujano del hospital de continuar con esta práctica.

La exención de botica ya había sido motivo de polémica. El importe de las medicinas despachadas para este capítulo entre 1783 y 1789 arroja una media anual de 2.500 reales (37). El establecimiento de la botica en el pueblo pareció influir decisivamente en el incremento de esta partida. Entre mayo de 1791, fecha de entrada en funcionamiento, hasta el mismo mes de 1795, la media anual se elevó a 2.889 reales. El ligero aumento se mantuvo en el bienio siguiente, para el que sólo contamos con el montante de exenciones excluidas las de los dependientes del hospital, y cuya media fue de 2.620 reales. A partir de 1797 se duplicó esta cifra. Entre mayo de ese año y el mismo mes de 1801, la media anual superó los 6.500 reales, situación que se mantuvo hasta octubre de 1802. Además, desde la creación de la botica del pueblo, los gastos derivados de esta prerrogativa corrieron por cuenta del hospital mientras que, en fechas anteriores, la Real Hacienda reintegraba su importe a las arcas del nosocomio. En 1802, el Hospital de Mineros, que comenzaba a padecer algunos problemas financieros, solicitó la remuneración de las recetas despachadas a los empleados con exención no pertenecientes al propio hospital (38).

Unos meses más tarde, el Superintendente ordenó a la Contaduría que indagase sobre los beneficiarios con derecho a la exención de botica. El informe confirma que ningún documento, salvo las ordenanzas del hospital de 1791, señalaba este privilegio, producto, más bien, del trato de favor dispensado por los boticarios a las máximas autoridades de la explotación. Incluso pesaba una prohibición expresa de 1761 sobre la venta gratuita a las casas de Superintendencia, Contaduría y Pagaduría (39). El informe con- 
cluye con una relación de los empleados con derecho a botica gratuita, 35 incluidos los del hospital y Almadenejos, sin que conste cual fue la decisión final del Superintendente, aunque todo apunta al mantenimiento de este privilegio. Unos años más tarde, probablemente en 1807, el colectivo de oficiales de mina solicitó la equiparación en "sueldos, obenciones y franquicias», entre ellas la gratuidad de médico y botica, con los oficiales de la Contaduría, pretensión que no fue concedida (40).

Por último, la documentación sobre exención de botica ofrece frecuentes referencias a los abusos cometidos por los beneficiarios, que obtenían por este medio alimentos incluidos en la composición de varias medicinas. Dos decretos del Superintendente y la Junta de Superintendencia, fechados en 1792 y 1799; respectivamente, prohibían despachar leche, aguardiente, zumos y otros alimentos salvo que formaran parte de recetas comprendidas en las farmacopeas (41).

Entre 1835 y 1838, los responsables de las Minas adoptaron un conjunto de disposiciones destinadas a desviar hacia el medio domiciliario, más barato, la responsabilidad asistencial. La restricción del acceso al nosocomio se acompañó de la concesión de ayudas diarias a los denominados «mineros incurables», un colectivo formado por trabajadores absolutamente imposibilitados para desarrollar cualquier tarea productiva. A pesar de su bajo número, apenas superaban la decena, eran los responsables de estancias de larga duración en el hospital (42). El endurecimiento del acceso aprobado en 1838 estimulaba a los facultativos a decretar la curación a domicilio con cargo a los presupuestos del hospital en caso de enfermos leves. Esta descarga de responsabilidades se acompañó de una reducción del presupuesto cuyo resultado no se hizo esperar. En noviembre de 1856, Sánchez Aparicio, médico-cirujano del Establecimiento, denunciaba el lamentable estado del nosocomio:

\footnotetext{
«Después de faltar hace muchos meses y de no repararse, a pesar de repetidas reclamaciones, muchos de los medicamentos más usuales para la curación de enfermos de este Hospital de mineros, así como algunos de los efectos y utensilios precisos para su asistencia, ha llegado a tal grado la escasez de algunos de ellos que en mi juicio sería poco honroso para el Establecimiento el que continuase en tal estado" (43).
}

Entre la relación de sustancias imprescindibles de las que carecía la botica se encuentran la quina, el sulfato de hierro, el bicarbonato de sosa "y hasta el alcohol». En cualquier caso, el informe revela que la escasez no 
afectaba exclusivamente a la botica. También faltaban colchones, ropas, mantas, amén de haberse reducido a 30 el número de camas. A pesar de las advertencias del facultativo sobre el "precio» de esta desasistencia (prolongación de las estancias, mayor número de inhabilitados) parece evidente que las modificaciones operadas en el mercado de trabajo durante las décadas centrales de la centuria cambiaron la actitud de los responsables de las Minas. En efecto, la presencia de un progresivo excedente de mano de obra desde mediados del siglo XIX, unido a las dificultades financieras, permitió a los dirigentes del Establecimiento reducir su contribución en los mecanismos reproductivos articulados desde la centuria precedente.

El testimonio de los ingenieros Bernáldez y Rúa Figueroa, que visitaron el Establecimiento en 1856, confirma la dedicación exclusiva de la botica al hospital, cesando por completo toda actividad de cara al público (44). Estas circunstancias se mantuvieron a lo largo de la segunda mitad de la centuria. El reglamento de 1904 señalaba la prohibición de dispensar medicinas a enfermos que no estuviesen ingresados en el hospital, con excepción de las suministradas a los mineros acogidos a la ley de accidentes del trabajo, en vigor desde 1900 (45).

Resulta evidente, pues, que la botica del hospital, al igual que el resto de recursos asistenciales instrumentados por las Minas, no permaneció al margen de las motivaciones utilitaristas que guiaron a los responsables de la explotación. Desde 1782, fecha de su creación, hasta 1810, momento en que la crisis financiera del Estado afectó seriamente al Establecimiento de Almadén, la botica ejerció un efecto multiplicador de la actividad desarrollada por el Hospital de Mineros.

\section{NOTAS}

(1) El estudio-de la relación salarial y mecanismos compensatorios vigentes en Almadén durante los siglos XVIII y XIX ha sido ampliamente abordado en DoBADo GonZÁLEZ, R. (1989), El trabajo en las Minas de Almadén, 1750-1855, (tesis doctoral, Universidad Complutense de Madrid), mecanografiado, 1241 pp., y Dobado GonZález, R. (1982), Salarios y condiciones de trabajo en las Minas de Almadén, 1758-1839. En: TEDDE, P. (ed.) La economía española al final del Antiguo Régimen. II. Manufacturas, Madrid, pp. 339-440.

(2) Un estudio detenido del proceso fundacional del hospital y su desarrollo en los primeros años de funcionamiento en MenÉndez NAVARRo, A. (1990), «El Real Hospital de Mineros de Almadén: génesis y florecimiento de un proyecto asistencial, 1752-1809", Dynamis, 10, 93-130. 
(3) Representación de 1675 sobre salarios y emolumentos de los trabajadores. A.H.N., Minas de Almadén, leg. 159.

(4) A.H.N., Minas de Almadén, leg. 80. Como veremos al analizar las exenciones de botica, el recurso de los boticarios en 1761 solicitando que se les eximiera de dar gratis los medicamentos a estos empleados, provocó la supresión de este privilegio; orden que, sin embargo, no se llevó a la práctica de forma estricta.

(5) A.H.N., Minas de Almadén, leg. 1.187.

(6) Constituciones y ordenanzas del Real Hospital de Mineros (1791). A.H.N., Minas de Almadén, leg. 1.193.

(7) Ibidem.

(8) Informe de Gaspar Soler de 5 de septiembre de 1781. A.H.N., Consejos, leg. 21.782.

(9) A.H.N., Minas de Almadén, leg. 87.

(10) Constituciones y ordenanzas del Real Hospital de Mineros (1791). A.H.N., Minas de Almadén, leg. 1.193.

(11) Matilla Tascón, A. (1958), Historia de las Minas de Almadén. Volumen I. (Desde la época romana hasta el año 1645), Mạdrid, p. 94 y Matilla Tascón, A. (1987), Historia de las Minas de Almadén. Volumen II. (Desde 1646 a 1799), Madrid, pp. 294-299.

(12) R.O. de 30 de septiembre de 1793. A.H.N., Minas de Almadén, leg. 200. No obstante, en 1798 los presos enfermos fueron de nuevo ubicados en esta dependencia, situación que se mantuvo hasta la supresión definitiva del presidio al final de la centuria. R.O. de 30 de agosto de 1799, «mandando que por ningún juez se condene reo alguno al presidio y trabajo de sus reales minas de Azogue en Almadén». Archivo Municipal de Pamplona, Bandos, leg. 11.

(13) A.H.N., Minas de Almadén, leg. 135.

(14) Constituciones y ordenanzas del Real Hospital de Mineros (1791). A.H.N., Minas de Almadén, leg. 1.193.

(15) Relaciones anuales del importe de las medicinas suministradas por la Botica del Real Hospital de Mineros de Almadén: A.H.N., Minas de Almadén, leg.10.

(16) Loc. cit.

(17) A.H.N., Minas de Almadén, leg. 1.143.

(18) A.H.N., Minas de Almadén, leg. 10.

(19) Relaciones anuales del importe de las medicinas suministradas por la Botica del Real Hospital de Mineros de Almadén. Loc. cit:

(20) A.H.N., Minas de Almadén, leg. 80. La fecha de creación en leg. 12.

(21) Libro de Acuerdos de la Junta de Superintendencia. A.D.H.E., leg.141.

(22) Informe de la Contaduría de 20 de mayo de 1800. A.H.N., Minas de Almadén, leg. 80 .

(23) Decreto de 9 de enero de 1801. Loc. cit.

(24) ORTuÑo, Clemente José de (1804), Plan de un nuevo gobierno eclesiástico necesario y provechoso a la Villa de.Almadén e intereses del Rey, ms., fols. 30-31. Esta obra ha sido objeto de un detenido estudio en Dobado GonZález, R. (1984), "Actitudes intelectuales frente a las condiciones de trabajo en las mirias de Almadén, 1760-1860», Revista de Historia Económica, 2, 59-89; pp. 63-78.

(25) A.H.N., Minas de Almadén, leg. 80

(26) Decreto de 24 de noviembre de 1812. A.H.N., Minas de Almadén, leg. 135. 
(27) Representación de la corporación municipal de 31 de marzo, e informe del Contador de 8 de abril de 1813. Loc. cit.

(28) Ibidem.

(29) Decreto del Superintendente de 7 de agosto de 1787. A.H.N., Minas de Almadén, leg. 10 .

(30) Decreto del Superintendente de 21 de julio de 1788. Loc. cit.

(31) Loc. cit.

(32) Dobado González, R. (1989), p. 599

(33) A.H.N., Minas de Almadén, leg. 10

(34) Ibidem

(35) Solicitud de la villa de Alamillo de 3 de septiembre de 1807, e informe de Basterra de 23 del mismo. Loc. cit.

(36) Decreto del Superintendente de 18 de agosto de 1834. Libro de Provincias del Hospital de Mineros de Almadén. A.D.H.E., leg. 231.

(37) Relaciones anuales del importe de las medicinas suministradas por la Botica del Real Hospital de Mineros de Almadén. A.H.N., Minas de Almadén, leg. 10

(38) Las cifras de exenciones desde 1791 a 1802 en A.H.N., Minas de Almadén, leg. 12.

(39) Informe de la Contaduría de 14 de marzo de 1803. Loc. cit. No consta la fecha en que se revocó la citada orden de 1761. Parece que entre esta orden y 1791, en que se produjo un decreto verbal del Superintendente autorizando de nuevo su entrada en vigor, el goce de la exención no era automático, sino que debía mediar autorización. Ello explicaría la elevación de los gastos a partir de 1791 .

(40) Representación de los oficiales de mina al Exmo. Sr. Don Francisco Saavedra (sin fecha). A.H.N., Minas de Almadén, leg. 159.

(41) Libro de Acuerdos de la Junta de Superintendencia, A.D.H.E., leg. 141.

(42) Providencia del Superintendente de 2 de noviembre de 1835 restringiendo el acceso de los trabajadores forasteros y sus familias; decreto del Director General de Minas, Rafael Cabanillas, de 21 de noviembre de 1838, sobre nuevas normas de ingreso al Hospital de Mineros; y R.O. de 27 de septiembre de 1837 sobre «mineros incurables»: A.D.H.E., leg. 231.

(43) A.H.N., Minas de Almadén, leg. 333.

(44) Bernaldez, F.; Rúa Figueroa, R. (1862), Reseña sobre la historia, la administración y la producción de las Minas de Almadén y Almadenejos, Madrid, pp. 108-109.

(45) Reglamento del Hospital de las Minas de Almadén (1904), Ciudad Real, pp. 15-16. 